\title{
EDITORIAL TO THE FIFTEENTH VOLUME
}

SINCE my editorial written in 1972 on the occasion of the Tenth volume of Paraplegia, our International Medical Society of Paraplegia has gone from strength to strength. This is reflected in particular in the ever-increasing number of papers read at the Annual Scientific Meeting of the Society, which has risen from 12 in I 962 after the foundation of the Society in I96I, to 43 in 1972 and in 1975 and 40 in 1976. Moreover, the number of original papers sent for publication has also grown. This, naturally, has increased the work of the editor and his staff, and I am particularly grateful to my assistant editors, Jim Cosbie Ross and Phillip Harris, who have been most helpful in vetting a number of the publications, which has greatly helped to maintain the high scientific standard of the fournal. Recently, Jim Cosbie Ross has been collecting abstracts sent to him from various colleagues of other journals concerning paraplegia and tetraplegia which will be published in Paraplegia. The Annual Scientific Meetings, held in conjunction with the Olympiad of the Paralysed, were attended by a particularly large number of colleagues in the Olympic years of 1972 in Heidelberg and 1976 in Toronto.

In addition to many proffered papers, special subjects have been chosen for discussion throughout the years, such as the subjects of Spinal Shock and Reflex Return, Spasticity, Classification of Spinal Cord Injuries, Stable and Unstable Fractures, Spinal Deformity, Associated Injuries, Anti-Coagulant Therapy in new Spinal Cord Injuries, Anaesthesia in Spinal Cord Injured Patients, Experimental Research of Spinal Cord Injuries in Animals and Man, Research on Sport, Urological Problems with special reference to the operative treatment of vesical outlet obstruction by transurethral resection and sphincterotomy; furthermore, Cardiovascular Problems, Sexual Problems, Home Care and Re-settlement, and Life Expectancy and Geriatrics in Spinal Cord Injured Patients. All this has, doubtless, increased our knowledge of the many aspects of the complex problems of paraplegia and tetraplegia.

In the immediate management of paraplegia and, in particular, tẹtraplegia, many workers with great experience in this field have raised their voices in recent years against indiscriminate, immediate surgery, in particular laminectomy, and indications for stabilising operations are becoming more selective. In this respect, the need for careful observation to prevent the development of deformities of the spine in the younger age-group has been stressed in the recent publications and the indications for stabilising procedures both conservative and surgical have been clarified.

The pathophysiology and management of the paralysed bladder and the upper urinary tract have played a particularly outstanding part in the publications throughout the years. Intermittent catheterisation is now increasingly established as the method of choice in the immediate and early treatment of paraplegia and tetraplegia, and the number of publications on this subject has increased not only in the discussions of the Society but also in other congresses. Research on dysreflexia with special reference to the cardiovascular system has continued with more sophisticated methods, which confirms the original findings in this important phenomenon. Considerable advances have been made in the treatment of vesical outlet obstruction. While Emmett's method of transurethral resection has still proved to be a very important procedure, it is the sphincterotomy, introduced by Cosbie Ross, which in recent years has found a greater application and proved most valuable in overcoming the peripheral obstruction. 
The increasing number of paraplegics and tetraplegics to be discharged from hospital has resulted in an ever-increasing problem of home care and social re-settlement. Here, society is still lagging behind, which results all too of ten in the re-admission of patients who have developed complications and unnecessarily increases the direct and indirect cost per patient.

This editorial cannot be closed without commenting on the problem of spinal paraplegia and tetraplegia as a specialty in its own right. There cannot be any doubt that, as a result of the work in Spinal Injuries Centres in many countries, this branch of medicine and surgery has for some years developed de facto as a multi-disciplinary specialty. However, the lack of official recognition of this specialty is detrimental to the future development of this complex branch of medicine, surgery and social medicine. If this were to be recognised by the Departments of Health as well as the Medical Authorities, it would attract the younger generation of members of the medical profession to take up this specialty as their life's work, as has been the case with other specialties concerned with treatment and management of specific organs, such as Ophthalmology, E.N.T., Chest Surgery, etc. In my long medical career I have witnessed the struggle of Neurology, which was previously either part of general medicine or Psychiatry, to be recognised as a specialty in itself, and the same applies to Neurosurgery and Orthopaedic Surgery, which previously were part of General Surgery. Through their work, these specialties have made great contributions to medicine and mankind. It is, therefore, ironical that the complex subject of spinal paraplegia and tetraplegia is sadly lagging behind other specialties in its official recognition. In recent years, some Universities such as Harvard (U.S.A.) and Heidelberg (Germany) have appointed the Directors of Spinal Injuries Centres as Professor in Spinal Injuries and Social Medicine and as Holder of a Chair in Rehabilitation respectively. Similar situations exist in Belgium and Poland, and Spinal Injuries Centres in Basle and Geneva (Switzerland), Perth, Sydney, Melbourne, Adelaide and Brisbane (Australia) and Toronto (Canada) are attached to University and Teaching Hospitals.

Therefore, it is of paramount importance that the International Medical Society of Paraplegia should increase its efforts to achieve official recognition of spinal paraplegia and tetraplegia as a specialty on its own, and one can only hope that allied specialties, in particular Neurosurgery, Orthopaedic Surgery and Urology, will unite to help in this effort, if only for the sake of justice to the many thousands of spinal cord sufferers.

Finally, in view of the ever-increasing problem of spinal paraplegia and tetraplegia, future editorials will appear at least once a year after each Volume.

This editorial cannot be closed without expressing my sincere appreciation of the great help Miss Joan Scruton, M.B.E. and Mrs Kate Lambrechts have given in my editorial work throughout the many years.

Sir Ludwig GutTManN 